\title{
Educated professionals of sustainability and the dimensions of practices
}

\author{
Janne J. Salovaara
}

Faculty of Biological and Environmental Sciences and Helsinki Institute of Sustainability Science (HELSUS), University of Helsinki, Helsinki, Finland, and

\author{
Katriina Soini \\ Natural Resources Institute Finland, Helsinki, Finland
}

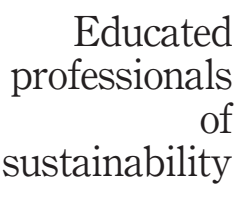

69

\begin{abstract}
Purpose - The purpose of this paper is to expand the competence-led structuring and understanding of sustainability education by analysing the practices of professional individuals who have completed university education geared to the development of sustainability change-makers.
\end{abstract}

Design/methodology/approach - The research scope was initially on examining professional practices following the boundary work theory. Social practice theory was used as a methodological approach in conducting and analysing thematic interviews with 19 sustainability-focused master's programme alumni. The interviews were analysed against the theoretical framework while also noting findings that fell outside of this framework.

Findings - A framework for understanding materials, competences and meanings of practices connected to the professional field of sustainability was introduced. The framework suggests that in the practices of sustainability-educated professionals, meanings emerge as a top priority and are conveyed using positionbased materials and various complexes of competency.

Research limitations/implications - The authors suggest that boundary theory informs well the emergence of the professional field of sustainability, and the utilisation of a practice theory furthers the understanding of sustainability professionalism and its education.

Practical implications - The authors' suggest that practice theory could thus provide deeper insights on how sustainability science alumni use their education after graduation, how they practice their profession and in return offer applicable reflections to sustainability education.

(c) Janne J. Salovaara and Katriina Soini. Published by Emerald Publishing Limited. This article is published under the Creative Commons Attribution (CC BY 4.0) licence. Anyone may reproduce, distribute, translate and create derivative works of this article (for both commercial and noncommercial purposes), subject to full attribution to the original publication and authors. The full terms of this licence may be seen at http://creativecommons.org/licences/by/4.0/legalcode

First, the authors would like to express their deep gratitude to Tiina and Antti Herlin Foundation for their continued support of this research.

The authors would also like to thank all Creative Sustainability alumni who took their time to participate in this research and for their willingness to engage in the reflective and candid conversations needed for the depth of this data.

Finally, the authors would also like to thank Sophia Hagolani-Albov for her assistance for proofreading this article, and the anonymous reviewers who gave their time, attention, and suggestions to improve the quality of this manuscript.

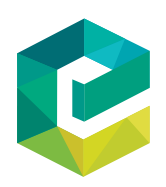

Received 3 September 2020 Revised 22 December 2020 29 January 2021 Accepted 29 January 2021 
IJSHE 22,8

Originality/value - Research using practice theory in reflection on sustainability education and the professional practice of sustainability has not been widely conducted and in the authors' opinion brings value to the education and practice of sustainability and to the research of sustainability education.

Keywords Sustainability education, Change-maker, Practice theory in education, Sustainability alumni, Sustainability professionalism

Paper type Research paper

\section{Introduction}

Education is recognised as one of our best bets in successfully reaching a society capable of existing in a state of sustainability (Meyer et al., 2016). As the field of sustainability-specific education develops (Disterheft et al., 2013), it has generated a widespread interest in the theoretical research on curriculums, pedagogy and competences (Wals and Jickling, 2002; Barth et al., 2007; Rusinko, 2009; Tamura and Uegaki, 2012; Leal Filho et al., 2016; Lehtonen et al., 2018). One branch of sustainability research and education, which can specifically be labelled as sustainability-centred, is found in the emerging discipline of sustainability science (Komiyama and Takeuchi, 2006). Sustainability science, in one of its many definitions, is a scientific initiative best defined by the problems it treats, rather than by the diverse disciplines it uses (Clark, 2007).

Competencies for sustainability have been one key focus of sustainability education research for studying the educational programmes and assessing the learning (Perez Salgado et al., 2018; Garcia et al., 2016; Soini et al., 2019). Key competencies to enact sustainability changes (Wiek et al., 2011) offer a framing mechanism that could be termed a competence-focused view of an education or professional field. Other approaches have also been expressed in sustainability education research, such as those that focus on the educational content and intended learning outcomes (O'Byrne et al., 2015; Ofei-Manu and Didham, 2018) or the pedagogy and teaching (Rahm and Gorges, 2018; Lozano et al., 2019) and some on the border between graduation and professional work, though from the competencies - or capabilities - perspective (Thomas et al., 2013; Willard et al., 2010).

As sustainability science emerges as a freestanding discipline (Fang et al., 2018), several educational programmes around the world have used its multi-, inter- and transdisciplinary approach to educate students to be "professionals of sustainability" (Salovaara et al., 2019). Sustainability science aims to be a transformative discipline (Wiek et al., 2012), educating its students in transformative programmes (Lotz-Sisitka et al., 2015) and overall aims to produce a new type of professional - one who is prepared to enter the job market poised and ready to further sustainability transformation (Heiskanen et al., 2016). These professionals, as the alumni of sustainability science education, are sometimes referred to as professional change-makers (Milkoreit et al., 2015) or change agents (Hesselbarth and Schaltegger, 2014). As the field is still emerging, both academia and in society at large, the question remains whether these professionals will form into a freestanding profession, similar to sustainability science as a freestanding discipline, or will they assimilate into other relevant and already established professions (Haider et al., 2018). Ultimately, what kind of professionals does sustainability education produce?

This research approached the professionals of sustainability science with a practicebased approach by examining their professional fields and activities. Professional fields are conceptually defined through boundary work (Gieryn, 1983). As boundary work is carried out within professional practices, it reinforces and distinguishes specific practices of a field from other practices and other fields. Thus, following Gieryn (1983), the authors conclude that practices are at the core of defining a profession. Practices, in turn, can be framed as 
functional constructs of materials, meanings and competencies (Shove et al., 2012). These elements of practices can assist in the capture and analysis of the potential distinctiveness of a professional field. The authors' suggest that practice theory could thus provide deeper insights on how sustainability science alumni use their education after graduation, how they practice their profession and in return offer applicable reflections to sustainability education.

The objective of this paper is to explore and showcase the multiplicity of sustainability practice with a broad take beyond the often-referenced competence-led process (Wiek et al., 2015; Trencher et al., 2018). To better understand professional practices of the educated change-makers, the authors conducted research among alumni of a master's programme oriented towards sustainability science. From the interview data, a practice-oriented framework for sustainability education was structured by studying the main materials, meanings and competencies of these sustainability professional's practices. As the research questions formed around the utilisation of social practice theory for sustainability education, the following main research questions were posed for this paper:

$R Q 1$. How can practice theory be used in exploring the sustainability professionalism?

$R Q 2$. What are the underlying structures of the practice elements in sustainability professionalism?

This study aims to offer a new perspective to sustainability education by highlighting an example of sustainability-centred education to professional practitioners from several different fields and bridging it back to the core elements of sustainability education through the framework of social practice theory. Simultaneously, the authors' aim to offer an overarching reflection on the practices implemented by professionals educated specifically in sustainability, bringing these reflections to a wider audience, especially those with an interest in nurturing the emerging professional field.

In Section 2, the authors introduce the two aforementioned theories in their original contexts and how they are applied in this paper. The authors then introduce the research context, data and methods of the content analysis. The key findings are introduced in sections divided by the research questions, and a short meta-analysis is offered under each section. Finally, the authors elaborate on the findings through a discussion of the implications of this research on the theory and practice of sustainability education.

\section{Theoretical background}

The authors ground this study in professional practices. Sustainability as a scientific discipline and as a professional field is emerging and yet somewhat undefined. Boundary work focuses on the self-produced and perpetuated practices at the core of a profession, whereas social practice theory conceptualises practices as complexes of materials, meanings and competencies, defined by the interdependent relations of these dimensions. Thus, exploring the dimensions of practices for framing the practices enacted by educated professionals of sustainability ought to reveal new insights of the professional field and education for sustainability. Thus, the motivation and background of the paper is informed by the boundary work theory, and it is used as lenses to understand the emergence of a professional field. The actual focus on the paper is how the practices shape the professional field, and here we use the social practice theory.

Gieryn's (1983) original paper addressed boundary work as a practice of rhetoric drawing boundaries between science and non-science. Practicing this type of boundary work was suggested as a constructive process over an emerging field to, for example, pursue 
IJSHE 22,8

authority, autonomy and career opportunities (Gieryn, 1983). Boundary work is practiced by scientists of a given discipline, for conceptualising their specialisation by drawing boundaries between what their field does and does not do. While professional fields are expandable and malleable (Fournier, 2002), exploring professional practices as a framing for an emerging field can yield insight, especially when exploring a field as a continuum of a specialised education. Professionals develop their practices in a self-perpetuating and selfproducing circle by changing, bettering, abandoning and adopting practices while justifying why those practices are needed, as well as why they are suitable professionals to enact these practices (Lamont and Molnár, 2002). Boundary work has multiple interpretations, and a key interpretation that comes into the field of sustainability suggests that transdisciplinary sustainability science ought to cross boundaries between knowledges (Offermans and Glasbergen, 2015; Meyer et al., 2016; Clark et al., 2016). Boundary work research in organisations has focused on professional boundaries, while the focus has been in practices as recognised and accepted routines of a profession (Zietsma and Lawrence, 2010). Thus, practices are at the core of a profession (Fournier, 2002). This theory seems meaningful to sustainability science and the education of sustainability science as it conceptualises a deliberate act in the process of creating a discipline. Boundary work, specifically focusing on practices, gives this research a focus in exploring the uniqueness of professional sustainability as an emerging field and the education that leads to this field. However, rather than focusing on the interviewees expressions of what they do not practice, the interviews focused on what the interviewees do practice in their profession.

Thus, an analytical framework was needed to study and analyse the professional practices. Shove et al. (2012) propose in their theory on social practices that professional development is relevant to the development of practices. Social practice theory aims to provide a framework of practices for the purpose of understanding their aims and changing them in a desired direction. The theory has been widely used in sustainability research for its potential to generate large-scale changes towards sustainability, which go beyond behavioural change approach (Shove et al., 2012). The theory suggests that practices are complexes consisting of materials (e.g. things, technologies), meanings (e.g. ideas, aspirations) and competencies (e.g. skills, know-how and technique). Practices change, emerge, shift and remain or disappear when the complex dimensions change. Practices can be explored through this framing and are definable by the dimensions and the relations between them. Similar applications of practice theory and the practices of sustainability that have been explored, for example, in the context of collective actions and how they emerge (Welch and Yates, 2018). This is specifically relevant to societal change, which in sustainability education focuses on the educational practices (Kemmis and Mutton, 2012) and the contexts in which the practices take place. This approach is most often used in the context of sustainable consumption (Shove and Walker, 2010) where transition is viewed through examples of sustainable practices rather than sustainable supply chains. Thus, the authors see importance in bringing practice theory to this context of sustainability, as it aims to be a transformative profession and educational endeavour. Practice theory is also an important framing mechanism to distil the structure of the emerging professional field of sustainability, with all its potential to help tackle critical environmental and other sustainability issues more effectively.

For the purpose of this study, the importance of practices needs to be understood in what are the underlying elements of the practices enacted by professional change-makers. As mentioned earlier, competencies are widely discussed in the context of sustainability education. They are defined as functional complexes of knowledge, skills and attitudes (Baartman et al., 2007) and are widely used in sustainability education research (e.g. 
Brundiers and Wiek, 2017; Trencher et al., 2018). The key competencies for sustainability (further explained in Section 4), which have been widely implemented in sustainability education, are suggested to be systems and futures thinking, and strategic, interpersonal and normative competencies (Wiek et al., 2011). Wiek et al. have also recognized the importance of the competencies to practically use the five key competencies for sustainability, as a sixth meta-competence (Wiek et al., 2015). In addition to these, Salovaara et al. (2019) found, through an exploration of the educational aims of sustainability science master's programmes, three competencies oriented towards sustainability science, which are diverse thinking, methodological plurality and entrepreneurial competencies. Through better understanding of the character of the competences, the other dimensions of practice theory and their materials and meanings need further empirical exploration in the context of sustainability education and the professionalized practice of sustainability.

\section{Material and method}

\subsection{Programme}

The thematic, semi-structured interviews were conducted with 19 alumni of a sustainability science-oriented master's programme, Creative Sustainability at Aalto University in Helsinki, Finland. This program, founded in 2010, was chosen as it has a relatively long history among sustainability-centred master's programmes in a Finnish context. The Creative Sustainability program brings together students from four fields to study sustainability in multidisciplinary teams:

The Master's Degree Programme in Creative Sustainability brings together students from different fields to study in multidisciplinary teams, increasing their understanding of different disciplines and enabling holistic approaches. This activates students to create new sustainable solutions for the human, urban, industrial and business environment. The pedagogical approach is based on integrating teaching and research, problem-based and blended learning and a strong connection to practical outcomes (http://acs.aalto.fi/masters-programme, accessed 1/2020).

The disciplinary divide guides the application process for the students and grounds their background studies to a particular professional field. Utilization of the existing departmental infrastructure offers the possibility for a more classical degree for the alumni, as the graduates from the programme graduate with Master's in Creative Sustainability, as a Master of Arts, Science, Economics, Landscape Planning or Architecture, based on their degree granting department.

The programme states using a multidisciplinary approach and claims design thinking, sustainability management and project management as their other intended learning outcomes. The studies are divided into the following four main types:

(1) compulsory joint studies to which all students participate;

(2) compulsory studies based on your department;

(3) alternative creative sustainability - studies where students have cross-department mobility; and

(4) elective studies where students can exercise their mobility across the university and other national and international universities.

Although the fields represented at the Creative Sustainability programme are more oriented towards applied sciences, the systems approach, interdisciplinarity between various disciplines and transdisciplinarity through strong contextualisation and collaborations orientate the programme as a sustainability science programme (Salovaara et al., 2019). In
Educated professionals of sustainability 
IJSHE

22,8

\section{4}

addition to these dimensions, the programme has a strong focus on sustainability practices and the career prospects of their graduates, even as they move into their professional career (http://acs.aalto.fi/masters-programme, accessed 1/2020). The fields where the alumni have continued post-graduation are diverse, representing consultancy work, doctoral studies, construction industry and employment and education services, among other professions. Almost no graduate seems to have an identical career, or study, even if they started on the same path.

\subsection{Interviewees}

The 19 interviewees graduated between 2012 and 2019 and represent several graduating classes of the programme, a range of professional, disciplinary and cultural backgrounds (Table 1). Some have already had a longer career, whereas others were at their early career stages. Close to half of the interviewees were Finnish, and the other half non-Finnish, reflecting the general student structure of the programme participants. Their base disciplines were divided as follows: design; 9 out of 62, business/management; 5 out of 38, built environment; 4 out of 22, and architecture; 1 out of 20 graduates over all graduated students. Rather than noting the graduation years, the sample was collected by the enrolment year as it is typical for the programme's students to finish their coursework within the two years projected duration of the programme but to finalise their thesis and graduate later. The interviewees were mainly recruited through a post in the alumni network seeking for volunteers to take part in this research, thus the number of interviewees was limited by access. However, to secure wider representation, some interviewees were approached specifically based on their backgrounds and enrolment year. Although, not all fields of study were equally represented, the interviewed graduates were working in several different fields after graduation. Thus, the practices from within - and outside - the programme are represented in the results observing the professionals, and the programme, as a whole.

The interviews took place between August and December of 2019 and were predominantly held in-person, with three interviews done remotely via audio and video call. The interviews all followed the same protocol of presenting the overarching theme and the three sub-areas of this research to the interviewee. The interviews ranged from $1 \mathrm{~h} 15 \mathrm{~min}$ to over $4 \mathrm{~h}$ and were audio-recorded, and extensive notes were taken during the interview. The free form discussions revolved around the themes represented in the research questions and were basically structured around three main questions focusing on the following:

(1) their study and career paths;

(2) their professional practices and their dimensions; and

(3) whether they considered themselves as sustainability professionals.

\begin{tabular}{llc}
\hline Nationailty & Field & Enrolement year \\
\hline Finnish: 10 & Design: 9 & $2010: 5$ \\
Non-finnish: 9 & Business/management: 5 & $2011: 2$ \\
& Built enrolement: 4 & $2012: 1$ \\
& Architecture: 1 & $2013: 3$ \\
& & $2014: 2$ \\
& & $2015: 5$ \\
& & $2017: 1$ \\
\hline
\end{tabular}

Table 1.

Interviewees by their background and enrolment year
Design: 9

Business/management: 5 2011:2

Built enrolement: $4 \quad 2012: 1$

$2014 \cdot 2$

2015:5 
These simple questions led into long associative and reflective discussion. The authors followed a qualitative research approach, with the intention to reach sufficient depth in rich insights from the interviewees (King and Horrocks, 2010) rather than a wide breadth of schematic data (Bryman, 2012).

As the overarching themes of the interviews closely followed the research questions, the analysis technique chosen was thematic content analysis (Hsieh and Shannon, 2005). The interviews were analysed, coded and indexed using the key themes under the three aforementioned areas. During the interview process, a separate interview analysis memo was kept (Bryman, 2012), primarily for noting the key points under the interview themes, and secondly to document the emerging thoughts interviewees brought up on, or around, the interview themes. As the major findings of the interview memo began to repeat, the authors determined that this indicated a level of saturation had been reached and the interviews were completed. The materials collected were then used to complete a secondary analysis focusing on the overall themes and concepts emerging from the content (Saldaña, 2009). This secondary analysis led to the groupings under the sustainability practices framework (Figure 1) presented in Section 5.

The corresponding author is a graduate of the programme. The authors consider this insider viewpoint as a strength, as this familiarity serves to deepen the understanding of the research context (Brannick and Coghlan, 2007). This expert interviewer/interviewee setting, through similar self-reflections, assured a shared understanding of the relevance of the topics (Bogner et al., 2009). However, it is important to note that as the interviewees were selected from different enrolled classes, neither author nor many of the interviewees were present in the programme at the same time. Thus, the interviewees do not represent a group as much as they represent a heterogeneous sample of the programme's graduates.

\section{Results}

The interview results are presented following the practice theory framework: materials, meanings and competencies, followed by an analytical reflection on each dimension of practice.

\subsection{Materials}

Materials as a dimension of a practice have not been framed specifically by previous research in the field of sustainability education or sustainability professionalism. Therefore, these results are based on the expressions given by the interviewees.

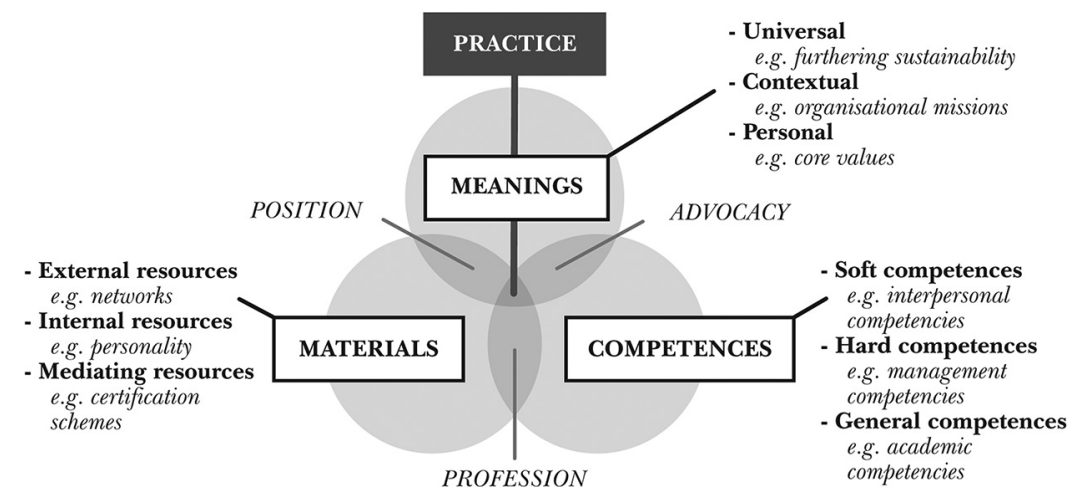

Figure 1. Diagram of the dimensions of sustainability professional's practices: materials, meanings and competencies with their structures and the overlapping areas of profession, position and advocacy 
IJSHE

22,8

Many of the interviewees initially cited practical materials, for example, their own brains for thinking and tools they use during their day-to-day work (e.g. computers, software, phones).

However, as the interviewees expanded and reflected on this aspect, they extended their interpretations of materials to include recognised knowledge and conceptualisations for substantiating sustainability. Examples that were given included using sustainable development goals (SDG) as a tool for conveying the importance of sustainability. This use of the SDGs was not field limited and was found to be used consistently by the changemakers, as Interviewee 16 described:

I use the certification scheme as my tool. It's written. It's a book I follow. I use that to navigate it. That's a good tool for me. [...] Kind of like these guidelines or tools that say that we didn't make it up ourselves. It really helps that the UN says this, or LEED says this, or BREEAM says like this.

Other regularly mentioned tools included presentations, visual communication, storytelling and various (co-)development and design tools and methods, such as lean innovation, innovation cards and canvases. Interviewee 8 explained:

Presentations and storytelling. That's where you can weave in those sustainability thoughts. In that kind of communication.

As the interviews progressed, the conceptualisations of materials continued to expand as networks of different kinds were commonly mentioned as resources of colloquial support, as comrades of the cause or as friends and collaborators. Interviewee 3 explained:

Those (networks) really benefit you in your work. Rarely there's a situation where you come across a thing or a subject where you don't know anyone who would know more about it.

Other external resources that were mentioned included knowledge and evidence from different sorts of sources, ranging from research to news and expertise to indigenous knowledges, as Interviewee 13 elaborated:

To me it matters to be open with the people I interact with at work. Trying to understand. So, one of my main tools is to try to listen to them first. [. . . Developing meanings through a dialogue.

In some cases, the organisations they worked for and the internal structures offered were seen as materials, as well as the resources they provide, such as funding for the sustainability work. Interviewee 19 described:

The ready built models and structures (of the organisation) really support this work. Without them I wouldn't have really known how to do the work I do now.

Another resource that was cited as internal and important was the role of their own personalities in how they approached their professional sustainability careers. Interviewee 2 elaborates:

Me as a person. What I am and what I represent. My experiences. My thoughts. My way of being present. My education and work experience.

Personality was seen as a vital tool to convey the cause which they worked for, and as a resource for self-learning and self-sufficiency, but also as part of other materials like voice and language to carry on practices and the meaning. Interviewee 6 stated:

I try to translate and word these things (of sustainability science) and then talk about them and discuss them through with people. 
Personality was also attached to another important resource, experience, which was seen as a material used often in the execution of the work.

What emerged from the interviews could be grouped into three main categories. First, materials such as persona and experience which could be grouped as internal resources of sorts. While the internal resources somewhat overlap with the conceptualisation of competencies, the authors saw them as aligning more with innate personal traits and features, rather than purely attainable abilities. Second, materials such as networks and the organisation itself which formed as a group of external resources. These resources correlate more directly with competencies as they are materially employable, but moreover they stand for structural and tangible materials related to the positional context. Third, materials such as SDGs and storytelling which were grouped as mediating resources. Mediating resources are materials that are mostly used through the competencies related more to the context of a practiced field (e.g. consultancy, service design).

\subsection{Meanings}

Meanings were noted from the interviews through ad hoc additions to the discussion topics, for example, why one is engaged in their chosen education, field, position, etc. The discussion had a typical progression of flowing from initial meanings around studying sustainability, to meanings developed when choosing a professional field and finally, to the meanings of why one remains engaged in the field and sustainability, observing these meanings as personal values.

The initial meanings mentioned in the interviews were those typical and closely aligned with the principle of sustainability. Some common examples of these are the concept of making the world a better place, responsibility over the future generations and well-being of fellow earthlings. Interviewee 11 described this connection:

As you worry about the future of the world, you want to affect [develop] those things that matter. To me the main matters are environmental change and equality in all [societal] aspects.

Often the meaning stated was akin to giving a meaning to the sustainability cause itself - in having a meaning to bring forward, apply and generate sustainability through one's profession and taking responsibility over the sustainability crisis. This was elaborated by Interviewee 6:

If you see that the things aren't fine and they're not going well, and you see and feel that you could possibly change things? It's in my nature to try to affect where I can.

Another more situational set of meanings arose when the interviewees reflected directly on a certain industry or a position. For example, working on a particular task within an organisation that holds sustainability as a key mission can be thought of as working for sustainability, even if the given task is not directly in sustainability, but rather being effective in the whole organisational structure that then generates sustainability as Interviewee 12 explained:

I've looked at the high-level goals of the platforms and the entity that I work for. And that it is about sustainability orientation, right? So that you can try to kind of scale down and up from your everyday work to service the higher goal above that. [...] So if the aims of the platform suit the sustainability agenda then the aims of the things, we do under the platform also match that.

Similarly, some interviewees saw that they can also work in an industry somewhat removed from the core of sustainability but still manage to work through and around their position, in driving sustainability. Interviewee 17 elaborated this by: 
IJSHE

22,8

If I think of my work now and probably in the future, it is ultimately human centric and interconnected. To understand people and get them to understand how they themselves can make the needed changes to their models and behavioural patterns. To co-create their pathway to there (sustainability).

The justification of the meaning and the engagement in specific professional practices to convey the meanings were also closely tied to personal values. Every interviewee, whether they self-identified as working at the core of sustainability, in a field related to it, or even removed from the field, all have aligned their work with their personal values. This sentiment was expressed succinctly as follows by Interviewee 4:

For me, I don't want to wake up and make the world a worse place. [. . .] I'm more into: "okay I want to do a job that is aligned with my values. That is not in confrontation with my values."

The interviewees brought up at least three different levels and scales where the meaning takes place and finds a target. First, the general and far-reaching meaning one would associate with the meaning of sustainability itself. These meanings derived from the sustainability principle which appeared as a level of universal meanings. Second, the meaning of applying sustainability to an industry, or an organisation and in a position, closely tied to the context of their work. These meanings derived from the organisation, position or field that emerged on the level of contextual meanings. Third, the meaning of working with sustainability through their personal life choices and values. This level of meanings, derived from core values, emerged as a level of personal meanings.

\subsection{Competencies}

In discussing the competencies most often used in professional practice, the authors used the suggested competencies by Wiek et al. (2011, 2015) and Salovaara et al. (2019) in the interviews. Further discussion was evoked in exploring competencies used in professional practices outside the suggested frameworks. This aforementioned framing of a competence, as a complex of knowledge, skills and attitude, has been commonly referenced in sustainability education research, which is why it was chosen over the framing suggested in social practice theory, which are skills, know-how and technique (Shove et al., 2012).

The most often mentioned competencies were interpersonal competencies, systems and strategic thinking and normative competencies. Interpersonal competence was most often mentioned with emphasis on collaboration. The fuller range of competencies for collaboration include the abilities to understand, communicate, negotiate, reconcile and lead different actors (Wiek et al., 2015).

Normative competencies, which are competencies to reflect, explain and negotiate sustainability, to apply and assess such underlying concepts as justice and fairness (Wiek et al., 2015) were also discussed as a major part of their professional practices. In particular, these were framed as important for negotiating, reflecting, defending and justifying sustainability for its place, possibilities and importance. Interviewee 15 described:

That you need to tell them [leaders], that surely you can plan your city like this, and that would lead to this and that. Or: you can decide differently and that would lead to [...][ ...] I would think as a professional, that you'd need to be able to communicate, to a normal person, why these changes are needed, that sure everything is okay now, but in 20 years they're in a mess.

Competencies for diverse modes of thinking were raised as an often-used approach, which is competence to approach the given problem in different modes, for example, creatively, outof-the-box and alternatively (Salovaara et al., 2019), as explained by Interviewee 11: 
If you want to do something new (things differently) and you want to change the world. That kind of change is something that people typically are scared of, and it requires bravery to challenge your own patterns and then even take [the outcomes] forward.

The conceptualisation of systems thinking included competencies to analyse problems from different domains and scales, to apply systems concepts to different contexts, such as ontologies, structures, effects and such (Wiek et al., 2015). This was highlighted as a commonly used competence to make sense of different subject matters, contexts, processes and projects. Interviewee 10 shared their experience:

It [systems thinking] gave me the theory and freedom to zoom out and look at what is the whole perspective [of the approach] and from there to draw boundaries around what needs to be concentrated on.

In this example, and in other practices for conveying their meanings, strategic competencies were found to be very important. Competencies that support autonomy were also mentioned, for example, competencies for self-directedness and resourcefulness, ingenuity, self-development and improvement (Salovaara et al., 2019). These competencies were highlighted through being an entrepreneur and finding their own path to practice professional sustainability but also in being part of an organisation, yet, maintaining an entrepreneurial approach to their profession. An example was given of working past their position to convey their meanings, by Interviewee 9 :

One thing that really helps me is just to be critical and specify what you want to solve and how you want to solve it? That's all I need, and there I go, and there's no excuses.

As part of the competencies for autonomy, traits such as being self-directed were also seen important to the field, these competencies include the will and ability to learn, re-learn and nurture curiosity. Pertaining to this approach, methodological plurality was also often mentioned in practices using several of the classical disciplines and moving across their borders, that is, being "interdisciplinary." Methodological plurality is demonstrated through the development of competencies for inter- and transdisciplinarity, to acknowledge and use different knowledges and methodologies (Salovaara et al., 2019). Interviewee 3 elaborates:

Every time I have been a part of a project, the feedback has been like: Wow, thanks for bringing this (project) together, and for filling in all the cracks. [. . . Y Your position has been such a valuable part of it. [. . . Even though you don't really have it (a specific position or role).

In addition to the selected competence frameworks, the interviewees mentioned several additional competencies they felt were meaningful in their practices, including the interpersonal, normative or even competencies for autonomy - depending on the context. The most mentioned competence, although heavily attitude oriented, was empathy. Empathy was consistently an issue that was discussed in its several different expressions, such as a prerequisite for understanding the plurality of sustainability from different perspectives or facing collaborators as equals and being compassionate. Interviewee 19 elaborated:

[The] ability to recognise your own biased thinking, and that your own understanding is based on something, and to move away from that, kind of like a designer stepping into the customer's shoes.

A competence for managing others and being able to act in a management role was also mentioned often, with examples such as managing a team or a project, as Interviewee 16 explained: 
IJSHE

22,8

I lead those projects [...] I cooperate with others and have one or two people helping me sometimes in my group but for us it means I'm responsible for the project to the customers and with the budget.

Although other forms of management, like self-management, conflict management, or the ability to manage expectations, were also mentioned. There was also a distinct competence which emerged based around having the experience of higher education, termed by the interviewees “academic DNA.” Interviewee 16 described:

I just think it's like the best skill you can learn is how to learn. Like to be really open minded because in real-life you're coming into a situation and it's like how to react and need to know something and like how to get new knowledge. What comes along? What do you need? That's the most you can do because I think the job will keep changing all the time.

Whether or not it could be considered a competence in an educational sense, an ability to manoeuvre in the idealism-realism dichotomy often found in sustainability related processes and settings was also found important, as Interviewee 17 told:

It takes a lot to further these issues, and to keep these things open and just on your mind all the time. That kind of internal activism, reminding yourself why you do these things in the first place.

It is important to note that this is a salient point whether it is gained directly and intentionally through education or learned through practice. This notion of idealism versus realism, or activism versus professionalism, was brought up on several occasions as an ideological issue. Although this juxtaposition was also discussed as an expression of the strategic competencies in whether one was able or unable to use or avoid these dichotomies. However, related to the strategic competencies, the ability to understand and manoeuvre in any situation at hand, that is, to have situational awareness about the project or your position within it, was mentioned as a useful and often used competence.

From these interviewees' reflections, the three dimensions emerge under the competencies for professional practices again. First, a dimension consisting of competencies such as interpersonal competencies and empathy, which can be labelled as soft competencies. These competencies are oriented towards conveying a meaning. Secondly, competencies such as management skills and competencies for autonomy were grouped as hard competencies, as they orientate towards a profession and were directly related to carrying out tasks and processes of a particular professional field. Thirdly, competencies such as academic skills were grouped as general competencies. General competencies were mentioned in regards to higher education, and the general competencies need to recruit.

\section{Discussion}

\subsection{Exploring the boundaries of an emerging profession}

A better understanding of the professional practices used by the educated sustainability practitioners - whom the authors refer to as sustainablers - in their working life serves to further focus on the foundations of sustainability education and exploring their effects on this new professional field. The development of a professionalised sustainability education and practice is connected to the larger academic and societal discussion of how academic knowledge is turned into tangible actions for sustainability (Kemmis and Mutton, 2012). This could be done by extending the educational framing from focusing solely on competencies disseminated in the educational environment to an integrated practice as a whole. 
The sustainablers are used in several different (professional) fields and positions, and consequently the content and idea of materials vary largely. Although they are still clearly part of the same professional repertoire of practices and they could be used using the same competencies and even for conveying the same meanings. However, some of the materials mentioned, such as the internal resources like the ability to learn or external resources, such as networks of colleagues or the use of methods and tools as devices like a computer, are utilisable universally. These three groupings of materials offer new depth to the understanding of professional practices. Overall, the materials were most often seen as elements that are tied to a specific field, i.e. their daily work in the current organisation, profession and position. In some cases, these materials were even seen as integral to the definition of the field, such as using design methods as a designer or a building certification scheme as a consultant in the construction field. The interviewees also recognised that the materials varied depending on the specific task, assignment or project, even though the field in which they were used remained the same. Thus, materials alone offer little to the boundaries between sustainability professionals and any other field where sustainability can be applied.

From the interview discussions, it became apparent that the meanings of the practices could be categorized on different levels: universal meanings such as intergenerational and universal well-being derived from sustainability principles; contextual meanings such as organisation and those derived from the profession and position; and personal meanings such as life choices and those derived from core values. Like materials, meanings under the practice theory seem to provide new insights into the possible meaning structures, although these levels of meaning are malleable. For example, in a case where the organisational sustainability mission trickled down to practices that were seemingly unrelated to sustainability, these practices were still perceived by the interviewee to convey the meaning of sustainability. Therefore, it seems that meanings are at the core of this specific profession and ought to be the substance to the boundaries with which the field mostly distinguishes itself from other fields where sustainability can still be a driver or an aim.

The competencies proposed in the interviews were generally well recognized by the interviewees. Several of the key competencies for sustainability emerged that are already well documented in the literature (Wiek et al., 2015; Salovaara et al., 2019), such as interpersonal and normative competencies, systems thinking and methodological plurality. Additional competencies also arose, such as empathy and an ability to manoeuvre the idealism/realism juxtaposition in one's profession. All of the competencies mentioned were categorised into soft, hard or general competencies. When competencies are seen as a part of practice, it becomes possible to pinpoint and use both soft and hard competencies of professionalism, and education, that might have been acknowledged, but lacked a proper framework. For example, distinguishing between interpersonal competencies utilisable in advocacy work ought to be approached differently in education than management competencies utilisable in a profession. Competencies are at the core of professionalism, but without the other dimensions of the practice (with the materials and meanings), they might not carry such decisiveness as to structure the boundaries of the sustainability profession.

While the professional sustainability practice can use any of the three elements materials, meanings and competencies - also individually, there is a bounded overlap and integration between the elements. Thus, all of them are needed to understand the professional field of sustainability. For example, competencies can be oriented towards using materials insofar as they are used to convey a meaning. However, the structures within each practice dimension - that is, the layers of meanings, classes of materials and types of competencies - are the key takeaways and pinnacles of development towards 
IJSHE 22,8

sustainability beyond one's isolated field or the projected career based on that discipline. Based on the interview findings, universal meanings emerge as ubiquitous to sustainability professionalism, where the elements of the materials or utilisation of their competencies differ contextually. Thus, one could generalise that the professional sustainability practices are best defined by their meanings, rather than just competencies or materials used.

Based on these results - structures around the three practices and their interconnection the idea of the sustainability professional's practices was further developed (Figure 1). Three overarching structures which aim to extend and clarify the idea of sustainability professionalism were identified. Profession refers to the professional field in which the practice is used and serves to connect the competencies to the materials, for example, management competencies are used in using certification schemes to a given project. Rather than a question of simply using competencies or using the scheme with a given competence, such a combination leans towards a definition of a structure of a profession. Position refers to one's professional post and also connects materials to meanings, for example, in the cases where networks are used to further the shared and universal meanings for a given context. Again, rather than looking at the isolated material or conveying a meaning, the combination defines a probable structure of a position. Advocacy refers to the goal orientedness of the specific professional practice and is essential in binding meanings to competencies. For example, this can be seen in using interpersonal competencies for using one's core values in a given problematique and thus lean more towards a definition of a created structure for advocacy than to the apparent dimensions of competencies and meanings.

Consequently, the sustainability profession emerges as a fluid conceptualisation of a professional field, wherein both profession and position can take different expressions when applied in the context of a conventional field. This is apparent in fields such as design or business, where a professional of sustainability can express their professionalism regardless of the field or position where they operate. Thus, there is plasticity in the practice of sustainability professionalism, when applying different methods, approaches, conditions and starting points to reach the desired goal (Woodfield, 1976) of conveying meaning. The practices, and perhaps the field of professional sustainability, are best defined by the meanings it conveys or the advocacy it enacts. This, in turn, creates an inherent level uncertainty within the typical definition of a profession (Fournier, 2002). This uncertainty is most succinctly summed up as a question of whether one is a professional of sustainability itself or a professional working in an already defined field that engages with sustainability. Focusing on the meaning rather than the competencies-oriented definition of the field emphasises the uniqueness of the profession and aligns well with the rhetoric theory of boundary work.

Based on the interview findings, the professionals felt strongly that their careers were least defined by the discrete position they held and most defined by the meanings their actions conveyed. Professionals still felt able to drive the meaning of sustainability and use their abilities in several different position-defined professions. Meaning, that regardless of a position, their career paths were, self-expressedly, narrated by sustainability. However, by the interviewees' experiences, sustainability is still juxtaposed against the more classical base fields and remains as "yet-emerging" rather than a recognised freestanding profession. Supporting the authors' views - and similar to a working definition of sustainability science sustainability functions as a field is defined by the problems it treats, not by the disciplines it uses (Clark, 2007). Sustainability professionalism is also defined by the meanings it conveys and not by the fields or the positions in which it is enacted. However, without the expressions of a field or position, the profession would only be defined by its advocacy to convey a meaning, which runs the risk of rendering a weakened image of professionalism. 


\subsection{Practice theory for sustainability education and professionalism}

In studying the practices of educated professionals of sustainability, sustainablers, the authors grounded their analysis in social practice theory and the materials, meanings and competencies framework therein. This division, in their view, reveals an utilisable understanding of the practice of an interdisciplinary, contextually adaptable and meaningsoriented education. Especially when considering that the professional practices entail several elements beyond the reach of education, such as internal resources, that can still be supported through education. Thus, this analysis of sustainability professionals somewhat reaches beyond the direct impact of the programme or the utilisation of its education. However, where more academic attention has been paid to the competencies, which is also validated by this research, the authors extend the scope by offering further insight on the materials and meanings directly reported from practicing professionals in the field.

Understanding the dimensions of the sustainability professional's practices, and the relations between them (Figure 1), brings the authors to suggest an expanded framing of the professional practice, in the context of sustainability education and professional development. What emerged from the results is that while educating competencies for sustainability is paramount, it seems equally important to deepen and structure the meanings through discussions and reflections and to have exposure and employability for different materials like networks and platforms, thus creating a full construct of practices in sustainability education that also applies to the context of sustainability professionalism. One can further convey the meaning(s) of sustainability by using the competencies and using the materials to create a meaningful education experience for practice-ready sustainability professionals and supporting a sustainable future.

What remains under debate is what would the utilisation of sustainability professionals be as a freestanding profession in comparison to assimilating sustainability to any and all other existing fields as a meaning-led orientation. This question, and the potential answer, ought to have an impact on the education and employability of the educated professionals and could in fact weigh the question of whether sustainability education reaches its goal, potential and expectations. Therefore, the authors recommend that further research is needed in what kind of professional image emerges free of the typical definitions, expectations and limitations of boxed-in, decisively defined professionals based on broadly recognised positions.

\section{Conclusions}

In this paper, the authors have analysed the professional practices of sustainabilityeducated change-makers by observing practices as a boundary work in an emerging profession. These professional practices were further analysed against a practice theory framework. The findings focused on the underlying structures of the practice elements in sustainability professionals.

The three groupings of materials: internal resources, external resources and mediating resources, offer new depth to the practice dimensions in the context of professional practices. However, materials in isolation, as one element of a practice, offer little to the boundaries between sustainability professionals and any other field where sustainability can be applied. Therefore, the competencies were further categorised into sets of soft competencies (e.g. interpersonal competencies), hard competencies (e.g. management competencies) and general competencies (e.g. academic competencies). Competencies are important to professionalism and thus remain at the core of constructing the emergent field of sustainability professionals. However, as with materials, competencies can be seen as insufficient in isolation to describe the emerging field. The meanings of professional 
IJSHE 22,8

practices were grouped into levels of universal meanings (e.g. furthering sustainability), contextual meanings (e.g. organisational mission) and personal meanings (e.g. core values). From an analytical point of view, meanings appear to be at the core of sustainability professionalism and lend substance to the boundaries that distinguish the field from other fields where sustainability can still be integral as a driver or aim.

The structures around the three dimensions could be used to develop education that is meanings-oriented and would enable professionals with better mobility to enact sustainability over a more typical mono-disciplined career prospect. Although seemingly repetitive, these structures emerged from the interviews and the analysis as key areas of discussion and reflection, even though they are not typically addressed in the theories of sustainability education or practices. Thus, the authors suggest that the practices need to be placed in the structures of the educational programmes where the practices are taught. These structures are the nodes that bind together different practices, using different materials and competencies per situation, yet they are all part of the same professionalism.

Using practice theory in exploring sustainability professionalism reveals a utilisable deep understanding of the practice of an interdisciplinary, contextually adaptable and meanings-oriented profession - and education. While more academic attention has been paid to the key competencies for sustainability, this research extends the scope by offering further knowledge of the materials and meanings empirically reported by educated and practicing professionals. Based on the findings of this research, focused through the boundary work theory and grounded in a practice theory analysis, the authors suggest a framework composed of practice theory elements for observing the emerging professional field of sustainability, and the education aimed to produce these professional changemakers, what the authors have termed as sustainablers.

\section{References}

Baartman, L., Bastiaens, T., Kirschner, P. and van der Vleuten, C. (2007), "Evaluating assessment quality in competence-based education: a qualitative comparison of two frameworks", Educational Research Review, Vol. 2 No. 2, pp. 114-129.

Barth, M., Godemann, J., Rieckmann, M. and Stoltenberg, U. (2007), "Developing key competencies for sustainable development in higher education", International Journal of Sustainability in Higher Education, Vol. 8 No. 4, pp. 416-430.

Bogner, A., Littig, B. and Menz, W. (2009), "Introduction: expert interviews - an introduction to a new methodological debate”, in: Bogner, A., Littig, B. and Menz, W. (Eds), Interviewing Experts, Palgrave Macmillan, pp. 1-13.

Brannick, T. and Coghlan, D. (2007), "In defence of being 'native', the case for insider academic research", Organizational Research Methods, Vol. 10 No. 1, pp. 59-74.

Brundiers, K. and Wiek, A. (2017), "Beyond interpersonal competence: teaching and learning professional skills in sustainability", Education Sciences, Vol. 7 No. 1, p. 39.

Bryman, A. (2012), Social Research Methods, 4th ed., Oxford University Press.

Clark, W. (2007), "Sustainability science: a room of its own", Proceedings of the National Academy of Sciences, Vol. 104 No. 6, pp. 1737-1738.

Clark, W., Tomich, T., van Noordwijk, M., Guston, D., Catacutan, D., Dickson, N. and McNie, E. (2016), "Boundary work for sustainable development: natural resource management at the consultative group on international agricultural research (CGIAR)", Proceedings of the National Academy of Sciences, Vol. 113 No. 17, pp. 4615-4622.

Disterheft, A., Caeiro, S., Azeiteiro, U. and Leal Filho, W. (2013), "Sustainability science and education for sustainable development in universities: a way for transition”, in: Caeiro, S., Leal Filho, W., 
Charbel, J. and Azeiteiro, U. (Eds), Sustainability Assessment Tools in Higher Education Institutions: Mapping Trends and Good Practices around the World, Springer, pp. 3-27.

Fang, X., Zhou, B., Tu, X., Ma, Q. and Wu, J. (2018), "What kind of a science is sustainability science? An evidence-based reexamination", Sustainability, Vol. 10 No. 5, p. 1478.

Fournier, V. (2002), "Boundary work and the (Un)making of the professions", in: Malin, N. (Ed.), Professionalism, Boundaries and the Workplace, Routledge, London and New York, NY, pp. 67-86.

Garcia, M., Junyent, M. and Fonolleda, M. (2016), "How to assess professional competencies in education for sustainability? An approach from a perspective of complexity", International Journal of Sustainability in Higher Education, Vol. 18 No. 5, pp. $772-797$.

Gieryn, T. (1983), "Boundary-work and the demarcation of science from non-science: strains and interests in professional ideologies of scientists", American Sociological Review, Vol. 48 No. 6, pp. 781-795.

Haider, L., Hentati-Sundberg, J., Giusti, M., Goodness, J., Hamann, M., Masterson, V., Meachamn, M., Merrie, A., Ospina, D., Schill, C. and Sinare, H. (2018), "The undisciplinary journey: early-career perspectives in sustainability science”, Sustainability Science, Vol. 13 No. 1, pp. 191-204.

Heiskanen, E., Thidell, A. and Rodhe, H. (2016), "Educating sustainability change agents: the importance of practical skills and experience", Journal of Cleaner Production, Vol. 123, pp. 218-226.

Hesselbarth, C. and Schaltegger, S. (2014), "Educating change agents for sustainability - learnings from the first sustainability management master of business administration", Journal of Cleaner Production, Vol. 62, pp. 24-36.

Hsieh, H.-F. and Shannon, S. (2005), "Three approaches to qualitative content analysis", Qualitative Health Research, Vol. 15 No. 9, pp. 1277-1288.

Kemmis, S. and Mutton, R. (2012), "Education for sustainability (EfS): practice and practice architects", Environmental Education Research, Vol. 18 No. 2, pp. 187-120.

King, N. and Horrocks, C. (2010), Interviews in Qualitative Research, Sage Publishing.

Komiyama, H. and Takeuchi, K. (2006), "Sustainability science: building a new discipline", Sustainability Science, Vol. 1 No. 1, pp. 1-6.

Lamont, M. and Molnár, V. (2002), "The study of boundaries in the social sciences", Annual Review of Sociology, Vol. 28 No. 1, pp. 167-195.

Leal Filho, W., Shiel, C. and Paço, A. (2016), "Implementing and operationalising integrative approaches to sustainability in higher education: the role of project-oriented learning", Journal of Cleaner Production, Vol. 133, pp. 126-135.

Lehtonen, A., Salonen, A., Cantell, H. and Riuttanen, L. (2018), “A pedagogy of interconnectedness for encountering climate change as a wicked sustainability problem", Journal of Cleaner Production, Vol. 199, pp. 860-867.

Lotz-Sisitka, H., Wals, A., Kronlid, D. and McGarry, D. (2015), "Transformative, transgressive social learning: rethinking higher education pedagogy in times of systemic global dysfunction", Current Opinion in Environmental Sustainability, Vol. 16, pp. 73-80.

Lozano, R., Barreiro-Gen, M., Lozano, F. and Sammalisto, K. (2019), "Teaching sustainability in European higher education institutions: assessing the connections between competences and pedagogical approaches", Sustainability, Vol. 11 No. 6, p. 1602.

Meyer, S., Levesque, V., Hutchins Bieluch, K., Johnson, M., McGreavy, B., Dreyer, S. and Smith, H. (2016), "Sustainability science graduate students as boundary spanners", Journal of Environmental Studies and Sciences, Vol. 6 No. 2, pp. 344-353.

Milkoreit, M., Moore, M.-L., Schoon, M. and Meek, C. (2015), "Resilience scientists as change-makers growing the middle ground between science and advocacy?", Environmental Science and Policy, Vol. 53, pp. 87-95.

Educated
professionals
of

sustainability

\section{.}


IJSHE 22,8

O’Byrne, D., Dripps, W. and Nicholas, K. (2015), “Teaching and learning sustainability: an assessment of the curriculum content and structure of sustainability degree programs in higher education", Sustainability Science, Vol. 10 No. 1, pp. 43-59.

Ofei-Manu, P. and Didham, R. (2018), "Identifying the factors for sustainability learning performance", Journal of Cleaner Production, Vol. 198, pp. 1173-1184.

Offermans, A. and Glasbergen, P. (2015), "Boundary work in sustainability partnerships: an exploration of the round table on sustainable palm oil", Environmental Science and Policy, Vol. 50, pp. 34-45.

Perez Salgado, F., Abott, D. and Wilson, G. (2018), "Dimensions of professional competences for interventions towards sustainability", Sustainability Science, Vol. 13 No. 1, pp. 163-177.

Rahm, J. and Gorges, A. (2018), "Educating science teachers for sustainability: questions, contradictions and possibilities for rethinking learning and pedagogy", Cultural Studies of Science Education, Vol. 13 No. 2, pp. 581-598.

Rusinko, C. (2009), "Integrating sustainability in higher education: a generic matrix", International Journal of Sustainability in Higher Education, Vol. 11 No. 3, pp. 250-259.

Saldaña, J. (2009), The Coding Manual for Qualitative Researchers, Sage Publications.

Salovaara, J., Soini, K. and Pietikäinen, J. (2019), "Sustainability science in education: analysis of master's programmes' curricula”, Sustainability Science, Vol. 15 No. 3.

Shove, E. and Walker, G. (2010), "Governing transitions in the sustainability of everyday life", Research Policy, Vol. 39 No. 4, pp. 471-476.

Shove, E., Pantzar, M. and Watson, M. (2012), The Dynamics of Social Practice: Everyday Life and How It Changes, Sage Publications.

Soini, K., Korhonen-Kurki, K. and Asikainen, H. (2019), "Transactional learning and sustainability cocreation in a university - business collaboration", International Journal of Sustainability in Higher Education, Vol. 20 No. 6, pp. 965-984.

Tamura, M. and Uegaki, T. (2012) "Development of an educational model for sustainability science: challenges in the mind-skills-knowledge education at Ibaraki University", Sustainability Science, Vol. 7, pp. 253-265.

Thomas, I., Barth, M. and Day, T. (2013), "Education for sustainability, graduate capabilities, professional employment: how they all connect", Australian Journal of Environmental Education, Vol. 29 No. 1, pp. 33-51.

Trencher, G., Vincent, S., Bahr, K., Kudo, S., Markham, K. and Yamanaka, Y. (2018), "Evaluating core competencies development in sustainability and environmental master's programs: an empirical analysis", Journal of Cleaner Production, Vol. 181, pp. 829-841.

Woodfield, A. (1976), Teleology, Cambridge University Press.

Wals, A. and Jickling, B. (2002), "Sustainability" in higher education: from doublethink and newspeak to critical thinking and meaningful learning", International Journal of Sustainability in Higher Education, Vol. 3 No. 3, pp. 221-232.

Welch, D. and Yates, L. (2018), "The practices of collective action: practice theory, sustainability transitions and social change", Journal for the Theory of Social Behaviour, Vol. 48 No. 3, pp. 288-305.

Wiek, A., Farioli, F., Fukushi, K. and Yarime, M. (2012), "Sustainability science: bridging the gap between science and society", Sustainability Science, Vol. 7 No. S1, pp. 1-4.

Wiek, A., Withycombe, L. and Redman, C. (2011), "Key competencies in sustainability: a reference framework for academic program development”, Sustainability Science, Vol. 6 No. 2, pp. 203-218.

Wiek, A., Bernstein, M., Foley, R., Cohen, M., Forrest, N., Kuzdas, C., Kay, B. and Withycombe, K., L. (2015), "Operationalising competencies in higher education for sustainable development", in: Barth, M., Michelsen, G., Rieckmann, M., Thomas, I. (Eds), Handbook of Higher Education for Sustainable Development, Routledge, London, pp. 241-260. 
Willard, M., Wiedmeyer, C., Warren Flint, R., Weedon, J., Woodward, R., Feldman, I. and Edwards, M. (2010), “The sustainability professional: 2010 competency survey report", Environmental Quality Management, Autumn, pp. 49-73.

Zietsma, C. and Lawrence, T. (2010), "Institutional work in the transformation of an organizational field: the interplay of boundary work and practice work", Administrative Science Quarterly, Vol. 55 No. 2, pp. 189-221.

\section{About the authors}

Janne J. Salovaara is a Doctoral student of Sustainability Science at the University of Helsinki, Finland. His research tackles the disciplinary development and education and impact of sustainability science. He critically examines the transformation potential, aims and impacts of the global sustainability endeavours. Janne J. Salovaara is the corresponding author and can be contacted at: janne.salovaara@helsinki.fi

Dr Adjunct Professor Katriina Soini is Principal Research Scientist and Research Manager working at Natural Resources Institute Finland. Her research focuses on sustainable natural resources governance from sustainability science perspective, with an emphasis on inter- and transdisciplinarity that aims for social learning for transformation.

For instructions on how to order reprints of this article, please visit our website: 